\title{
Introduction to this Special Issue Cultural Diplomacy: What Role for Cities and Civil Society Actors?
}

\author{
Yudhishthir Raj Isar ${ }^{1}$ • Anna Triandafyllidou ${ }^{2}$ \\ Published online: 7 October 2020 \\ (C) Springer Science+Business Media, LLC, part of Springer Nature 2020
}

Cultural diplomacy as discourse and practice looms large today in both cultural policy studies and international relations. In effect, the term cultural diplomacy is widely used, so much so that it has become a floating signifier, commonly deployed by foreign policy establishments and the arts and culture sector alike (Isar 2010).

Cultural diplomacy has become an ambivalent concept with blurred boundaries. A more traditional definition of cultural diplomacy sees it as a soft power tool through which states and/or international organizations pursue foreign policy objectives. Cultural diplomacy in this perspective would be limited to the processes that occur when formal diplomats, operating at the service and in the name of their governments, use cultural resources to help advance national interests. But in recent years, an expanded and more self-reflexive definition has prevailed which conceives it as a policy area in its own right, which promotes quality of life, the arts, joint capacity building, economic growth and social cohesion by engaging citizens and civil society actors, across borders, both as producers and consumers of cultural activities. This expanded definition of cultural diplomacy uses exchanges of cultural goods and services, cooperation and networking among museums, cultural foundations and ministries, artists and curators from different countries and continents, to promote better and closer relations and extend their overall societal and political influence. Even in this extended form though, cultural diplomacy activities may also be used to advance specific geopolitical interests or to buttress trade policy (Ang et al. 2015).

Earlier, the two definitions and the processes related to them were seen as distinct by analysts. The former was defined as cultural diplomacy and the latter as international cultural relations, which remain based on flows of cultural exchange but take place naturally and organically, without government intervention. As the distinction has become blurred both in policy and scholarship, the attention of researchers has remained directed mainly at exchanges

Anna Triandafyllidou anna.triandafyllidou@ryerson.ca

Yudhishthir Raj Isar risar@aup.edu

1 Department of Global Communications, The American University of Paris, Paris, France

2 Canada Excellence Research Chair, Ryerson University, Toronto, Canada 
between countries and at cultural programmes and overall cultural activities taking place between and among nation states. This form of 'methodological nationalism' has led to two major lacunae, both of which merit further debate and research. The first of these is that there is very little direct analysis of the motivations, values and efforts of civil society actors. The second is the relative absence of research on how cities are now practicing international cultural relations and diplomacy among themselves-and they are often doing this via the agency of civil society actors. With a view to addressing these interconnected gaps, a workshop was organized by the guest editors at the Robert Schuman Centre for Advanced Studies at the European University Institute, Florence, Italy, on 21 May 2019. This was a point of departure. This special issue now brings together the contributions made to that discussion and that have been further developed by eight authors.

\section{Civil Society Actors in Cultural Diplomacy}

Today, many non-state actors, non-governmental organizations, artists and arts organizations profess to practice cultural diplomacy, despite the fact that their professional and artistic relations with counterparts in other countries are driven far more by the desire for peer-topeer collaboration and exchange across borders rather than being consciously designed to serve any aspect of the 'national interest'. Their motivations in working internationally revolve around mutual learning; pooling of resources; co-financing; technical assistance; joint reflection, debate, research and experimentation; and cooperation in creative processes, the creation of new artistic works. So how committed are they really are to singing government-led tunes?

To be sure, artistic self-identification with the practice of cultural diplomacy is partly or even largely opportunistic, since claims to be performing cultural diplomacy has become an open sesame to support from official sources. But there is also a kind of cognitive and emotional attachment to this vogue term. Civil society efforts in this arena are therefore often ambiguous, and this ambiguity itself suggests the need for further research.

A first issue that one would need to tackle is what we mean when we speak of civil society organizations in the area of cultural diplomacy. One is clearly thinking of cultural associations rising at the grassroots level to promote the artistic creation of specific groups of people, but one may also consider in this area the role of private not for profit foundations of different types that may be active in the cultural arena either as promoters of cultural exchanges or as themselves creators/supports of different forms of culture (including, for instance, painting but also digital design, cinema or music, theatre or street performances). And how does one ascertain that such actors engage in cultural diplomacy? For instance, some of these cultural associations or foundations may include international exchanges among their main objectives. While for others, such activity may arise out of a specific opportunity context. And while for some organizations, international cultural relations or indeed cultural diplomacy proper may be part of their primary objectives and their raison d'être, for others it may be merely an occasional engagement, a side effect of other core activities that remain local or national.

In addition, the boundaries can be blurred between new types of cultural actors such as museum curators (see also Jérémie Molho in this special issue), whose role has been expanding and becoming increasingly important but who may not be classified as belonging to civil society proper, and private sector actors such as the corporate social responsibility branches of large corporations that promote and support cultural activities both nationally and internationally. The role of foundations, whether private or corporate, can also be quite 
ambiguous depending on their (in) dependence from governments (see also Peggy Levitt and her co-authors in this special issue) or from multinationals, or indeed from major philanthropists with their own agendas.

\section{Cities as Cultural Diplomacy Actors}

Not only are more people living in cities than ever before, but city powers (literal and symbolic) are increasingly displacing the power of the national in a multitude of different registers. Yet most writers on cultural affairs still take nation states as their principal units of analysis. Many analysts have long reminded us, however, that it is high time to abandon the methodological nationalism inherent in studying processes such as cultural relations and cultural diplomacy as if they were processes that could be contained entirely within the borders and foreign policy objectives of nation states. In these processes, as in many others, cities have become leading loci of policy making and governance. Changing patterns of cultural behaviour have led inter alia to new localisms on the one hand, or to manifestations of the 'glocal' on the other. These are hybrid forms, styles and patterns bringing together local and global elements and processes. Many cities are creating their own imagined communities and aspiring to become part of a broader global 'community' —or 'network' of cities—that is not marked or limited by state and/or national borders.

Scholars such as Çaglar and Glick Schiller have applied the term 'rescaling' to the ways in which the status and significance of cities are being repositioned, both in relationship to nation states and within global hierarchies of urban-based institutional power. They also make a direct link to migration, by addressing the ways in which 'individual migrants, the networks they form, and the social fields created by their networks... as systems of social relations composed of networks of networks that may be locally situation, or may extend nationally or transnationally' (Caglar and Glick Schiller 2015). This agency on the part of migrants becomes an important factor in the rescaling process, 'contributing to a re-evaluation of a city's global image' and making migrants a 'marketable asset', while also bringing multiple 'transnational connections that can link cities to flows of capital, goods, ideas... and cultural representations', hence the need to 'systematically investigate both variations in migrant pathways of incorporation and transnational connection and the impact migrant pathways have on the efforts of a particular city's leadership to reinvent and reposition their city'.

Addressing such repositioning in the city management perspective, the city network EUROCITIES, which uses the European Commission's favoured euphemism of 'external cultural relations' instead of the term 'cultural diplomacy', carried out a study in 2017 entitled 'Cities' external cultural relations: trends and actions'. The study highlighted the roles of thirteen European cities in developing and maintaining cultural relations with other cities around the world. It claimed that these cities are laboratories for new ways of working, as their size and status make them important actors on the global stage, while their proximity to citizens allows their policies and actions to be responsive and innovative, enabling them to act as 'early adopters' of new pathways of interaction. The study also made the possibly dubious claim that these cities practice 'engaging rather than showcasing', as they find new pathways of collaboration and co-creation to replace the showcasing that is traditionally associated with cultural relations and cultural diplomacy. As a pan-European body, EUROCITIES also makes a third claim, that these cities are conveying European values outside the European Union (EU) through a city to city and citizen to citizen model (EUROCITIES 2017). 
The study also made a pitch to the EU on behalf of European cities, citing them as brokers and facilitators for contacts between local cultural institutions and their counterparts in international partner cities, mirroring the multi-stakeholder approach propounded in the EU's proposed strategy for international cultural relations. Cities bring stakeholders together, pursued the study, maximizing their potential through collaboration, ensuring complementarity in much the same way as proposed in the conclusions of the European Council for an EU strategic approach to international cultural relations. The study also argued that city authorities are major potential partners for such pilot projects and future EU actions in the field of international cultural relations on the cutting edge of innovation.

Claims such as these need to be discussed critically. They have in fact become universal. Although currently articulated most forcefully at the level of the European Union, such claims are now being made by city authorities across the entire world. They have also begun to be studied by a handful of cultural scholars. There is a clear link here to the first theme. What is the role of cultural operators and producers in the city context? Are they the lynchpin in helping make actual relationships develop rather than indulging in performative posturing ('engaging rather than showcasing')? Could the experience of cultural operators and producers be more fruitful than that of policies/policy makers in understanding the promise and contradictions of cultural diplomacy today? Could the experience of individuals and their professional networks direct us to the most interesting questions?

\section{Cultural Diplomacy as a Bourdieusian Field?}

It remains necessary, however, since cultural relations practiced by civil society actors have received scant scholarly attention, to identify a theoretical lens through which the cultural relations of civil society actors can be analysed in greater breadth and depth. Bourdieu's field theory offers a suitable conceptual and analytical lens for critically understanding the role of civil society and city actors in cultural diplomacy. For it addresses questions that the study of culture and cultural processes all too often ignore, questions about the interests at stake for individual and institutional agents and 'about the mechanisms and stratagems by means of which these interests assert themselves, and the ultimate role that such cultural assertions of interest play in maintaining or altering the social distribution of power...' (English 2005: pp. $8-9)$.

A Bourdieusian field is a 'space of play', but it is also 'simultaneously a space of conflict and competition' (original emphasis). Agents struggle for the forms of capital that are at stake, the possession of which determines the power they are able to wield, i.e. the influence they are able to exert. The outcome of a struggle between agents depends on the capital each holds, as well as the skill with which they play the game. While a field may be a 'space of play', the structure of the field itself depends on the 'relations of force between players', and the distances, gaps and asymmetries between positions in the field. The positions that agents occupy in the field are determined by the capital that each holds and the relations of power between them (Bourdieu and Wacquant 1992; Kloot 2009).

The outcomes also depend on the structure of the field, the 'lie of the land' at that moment in time. Agents who dominate the field are better able to impose their particular forms of belief in the game and its stake and are therefore in a better position to reap the rewards of the game. While the term 'struggle' may seem excessive when applied to the triangular relationships between and among cultural operators, the case studies presented 
in this special issue highlight some of these tensions, competitions and struggles to dominate the field.

The empirical evidence culled already from actually existing cultural civil society practice, although limited, warrants the deployment of the theory as a conceptual, analytical and explanatory tool in order to go further. The 'field' can be seen to consist of several assemblages of players: arts organizations engaged in cultural relations together with national cultural institutes, all of which in turn are overseen and funded, sometimes also driven, by governmental entities, mainly ministries of culture, but also, increasingly, by municipal authorities, as well as private sector sponsors. This 'field' is clearly seen in the cultural diplomacy activities of the last couple of decades in Europe (see also Isar forthcoming).

Turning to other continents, as our special issue engages with civil society actors in North America (Smith, Levitt and Selch in this volume), or city actors in Morocco (see Dines in this special issue) and Turkey (see Caglar in this special issue) as well as private curators (see Molho in this special issue) in Doha and Singapore; the landscape is different in the details, but structurally it is largely the same. On both sides of this divide, it is possible to see all three forms of Bourdieusian capital in play, as the 'game' of cultural relations is played, and transmutations between and among the different forms of capital take place. In the different cases presented in the pages that follow, cultural capital, and to some extent social capital as well, resides within the cultural field, while both are defined in terms of cultural criteria of valuation. They are largely 'autonomous' in Bourdieu's sense. They are largely 'autonomous' in Bourdieu's sense, whereas heteronomous economic capital deploys its force essentially beyond the space of the arts and artistic exchange, while bearing upon the cultural and social axes rather heavily and lending itself to transmutation into cultural and social capital. Further scrutiny, then, should enable us to go beneath the surface of the cultural relations 'system'.

Bourdieu often used the analogy of a playing field for a team sport. This idea implies boundaries. And within that bounded space, a range of position takings where the cultural operators concerned affirm or shape their identities and hierarchical positions - always in relation to other actors - notably those from whom various forms of support, mainly financial, are expected. And within which players are guided by certain conventions, or rules (which are often implicit regularities) as to what sorts of stances or 'moves' are allowable. By likening social activity to a game, Bourdieu did not mean that there is a formal agreement by which agents enter into the game, or a set of codified rules by which all agree to play. Almost unconsciously, agents play the game by virtue of their doxa, their beliefs in the game and its stakes. Because of their investment in the game, what Bourdieu called illusio, they compete with one another, but always according to the implicit, unspoken rules of the game. While the term 'struggle' could appear too strong to characterize the relationships between and among cultural operators, city governments, national ministries and private foundations, it is safe to say that competition does exist in this arena, and at several levels.

These sorts of issues were tackled frontally by Mike van Graan, the South African playwright and cultural activist. Himself endowed with considerable authority because of his activist leadership and writing, this author commented on the international cultural relations landscape in the following terms:

Cultural or artistic collaborations and exchanges do not take place in vacuums. Particularly in contexts characterized by inequality between partners, collaborations are impacted upon in terms of skills, resources, infrastructure, working conditions, networks, experience, etc.... Overt or unspoken power relations have the capacity to derail 
the artistic collaboration or to influence its aesthetic outcomes. In Global North countries, culture is used by some institutions officially to promote certain 'values', but implicitly to defend precise interests... [and] determine the wording used by organisations is less-resourced countries in order to access funding opportunities, aligning their priorities to fit guidelines that do not actually correspond to their own reality. (Van Graan 2018, p. 8)

Finance is not the only realm where asymmetrical relationships and inequalities of cultural capital operate; such imbalances also present in the realms of aesthetic judgement, artistic strategy, relationships with artists and audiences, as regards reciprocity of benefits, shared responsibility and ownership, and in styles and rules of management, inter alia.

It is appropriate to cite here, in a field theory framing, insights from Lisa Gaupp (2020), who has explored how different concepts of diversity reign in the curation of performing arts festivals and how this curatorial practice is influenced by power relations, conventions, network structures and network processes. When Western festival curators deal with 'non-European' or non-'Western' performances, she asks, how do they define and normalize diversity and the way it is programmed? Unsurprisingly, Gaupp finds that, on the one hand, there is a strongly Eurocentric or 'Western'-centric canon with regard to what kinds of aesthetic forms are curated. On the other, there seem to exist both normative definitions of diversity and conventions of diversity based on the global circulation of financial capital. How diversity is defined is also deeply dependent upon the cultural and social capital, tastes, dispositions, beliefs and perceptions of individual curators, who are the key cultural intermediaries in Bourdieu's sense. It is not curators alone, however, who define diversity but also the processes and structures surrounding curatorial practice that ultimately contribute to the choice of what is appropriate to programme and what is not. Any cultural intermediary often striving to legitimate the 'not-yet-legitimate', as her work as a taste maker, reconfirms her own cultural capital and thus her position.

The conventions that establish how diversity is to be read and how it is then staged for an audience seem to posit that national origin is irrelevant and that a festival should be a space of ecumenical inclusion. Yet, when it comes to valuing differences, curators tend to opt for productions that are 'different enough' to fulfil the demand for the unfamiliar, but 'not too different'. Gaupp cites one curator who thought that showing African artists would be 'boring' for her audiences, arguing that the latter would be too unfamiliar with the requisite 'African' aesthetic language to be able to understand its particular conventions. This curator went on to say that other cultural organizations could show such artists, because they have established a 'tradition' of educating their audiences about such art forms. Is it possible then, the author asks, to get away from the convention of 'different enough-but not too different' in the curatorial practice of performing arts festivals (Gaupp 2020, pp. 127-149)?

Curating envisaged as a transcultural process of inclusion would need to be driven by both distance and critique. It would legitimize conflict as part of engaging with 'new' art forms. So the feared unfamiliarity of an art form or even the unconsciously biased conventions within curatorial practice could themselves become topics of exploration. Transcultural diversity in this sense does not mean ignoring inequalities or discrimination, but accounting for them fully in a transcultural diversity-sensitive approach that privileges 'cultural overlaps, border spaces and spaces-in-between, of crossings and simultanious affiliations'. For curation constitutes a complex sub-field of cultural relations in which different practices intermingle, multiple 
networks obtain, and dominant ideologies, terms, and habits are produced and reproduced, while the curator herself also plays a role in defining or redefining conventions.

The preceding analysis, itself largely inspired by key notions within field theory, exemplifies the kind of additional ground that could be covered by deploying the theory systematically to make sense of the role of civil society and city actors in the field of cultural diplomacy. This deployment could involve questions such as the following. How does the field and the sub-fields that constitute it actually operate? How are social relations structured within them? What cultural and social rewards do they offer to participants? What are the rules of the game that need to be followed if such rewards are to be attained? Which actors are trying to change these rules? Which actors hold what kind of authority? What new position takings are appearing within the field to possibly renovate it? How do these possibly alter the shape of the field and create new possibilities (Gibson and Moore 2018)? What forms of censorship (understood as the obligation to produce discourse that respects the forms and formalities of the field) are to be detected in the way cultural relations actors talk and write about what they do (Bourdieu 1992)? These are some of the research questions that could be asked. Carrying this line of inquiry further could uncover changing configurations and fault lines with regard to both the doxa and the illusio as perceived, lived and represented by cultural actors in different parts of the world as they become enmeshed in an ever more developed web of cultural diplomacy.

\section{In this Special Issue}

This special issue seeks to begin such a conversation by analysing the role different civil society and city actors in different world regions and how their relations in the urban, national and transnational environment have evolved. It opens with Robin Brown's historical sociological overview of the origins and the 'politics' of cultural diplomacy, which offers an appropriate background for us to consider how the notion of field as proposed by Bourdieu and the power relations within can find their roots in the genealogy of the concept and practice of cultural diplomacy. The paper 'Civil Society and Cultural Diplomacy: Towards a Historical Sociology' argues that while the term 'cultural diplomacy' is familiar today, it was infrequently used before the end of the Cold War. In fact, practitioners avoided the term and preferred 'cultural relations'. Brown explains the rise of 'cultural diplomacy' via a historical sociology of the broader field of 'cultural statecraft'. His analysis shows that during the interwar period, two modes of cultural statecraft emerged with distinct organizational configurations: 'cultural relations' that embedded 'culture' within the field of foreign policy and 'intellectual cooperation' that sought to de-nationalize culture. Within the cultural relations area, the key relationship was between foreign ministries and semi-autonomous implementing agencies. In this context, 'cultural relations' served to manage the arms-length relationship between the two sides. At the end of the Cold War, changing policy ideas and the development emerge of an organizational model based on projects brought new actors into the field for whom old sensitivities around cultural diplomacy are no longer applied.

Starting from the Cold War era but extending to recent times, Sarah Smith, Peggy Levitt and Rebecca Selch offer in the second paper, entitled 'The Imagined Globe: Remapping the world through public diplomacy at the Asia Society', an in-depth analysis of this cultural organization. Founded by John D. Rockefeller 3rd in 1956, the Asia Society was established to educate Americans about Asia at a time when there was much less contact between the USA 
and Asia than there is today. Since then, the institution has undergone several reinventions, each contributing to and reflecting changing understandings of Asia and its relationship to the USA. In their analysis, Smith and co-authors track the kinds of artwork that the Asia Society collected and put on display, the range of countries it categorized as Asian, and the goals and content of its programming, to reveal these shifts in scale and focus and demonstrate how they mirror and drive forward shifts in US-Asian relations. The study also explores the intertwining of cultural, diplomatic and economic elites in this process. The paper shows how cultural institutions may act both as a catalyst and a reflection of changing political economic dynamics that, in turn, shape how citizens imagine their world and their nation's place within it. Smith, Levitt and Selch argue that cultural diplomacy has been and still is an aspect of public diplomacy often overlooked.

Similarly, the third paper by Ayse Caglar entitled "Situating the 'cultural reach' of cities in a multi-scalar field" scrutinizes the emerging landscape of local as well as transnational connection building in the arts and culture within the dynamics of neoliberal city-making. In so doing, she addresses the danger of 'methodological nationalism' yet also questions state-civil society binaries with a view to showing the complexity of the policies and practices of city actors as they are imbricated with that of state actors. Caglar argues that a multi-scalar analysis at the local and translocal level is required so as to situate exchange narratives and networks within a broader context of (a) neoliberal transformations within which the power and the location of states have been reconfigured; (b) value regimes closely entangled with the processes of wealth generation, particularly within cities; and (c) the power geometry of a particular historical conjuncture. Mardin, a border city in Turkey, offers a particularly suitable venue in which to analyse these dynamics. The paper explores the political economy of the city's 'cultural reach' by connecting the dynamics of cultural production to value creating processes in and through urban regeneration to understand when, how and which groups and sites become de- and/ or re-valorized. It highlights the futility of nation state-city, state-civil society binaries in analysing the power geometry of multi-scalar actors involved in the work, efficacy and the potency of cultural networks, institutions and cultural diplomacy.

Shifting the lens further eastwards, Jérémie Molho in his paper 'Putting the City on the World Art map: Star Curators and Nation Branding' focuses on two special cases, namely Qatar's capital Doha and the city-state of Singapore. The recent worldwide expansion of the concept and practice of cultural diplomacy, along with the emergence of a multipolar world, makes it necessary to question the way in which the notion is mobilized and understood beyond Europe and North America, he argues. The author's comparative research carried out in Qatar and Singapore reveals that both have developed ambitious cultural diplomacy strategies, based on the establishment of world-class cultural and educational institutions, and on their integration into regional and global cultural networks. But many analysts have highlighted the contradictions between such strategies and the restrictions and pressures that both these countries place on their civil societies. Focusing on curators, Molho discusses how they negotiate their role and position themselves with regard to the official national narrative. In a globalized art world, curators have emerged as key global gatekeepers. With their multiple belonging, they shape narratives that make regional and local scenes and can put cities on the world art map. This symbolic power puts them in a strategic position to shape the nation branding discourse. Qatar and Singapore are both modern but at the same time traditionalist, illiberal but also 
cosmopolitan; the analysis shows how curators manage to expand the boundaries of the national narrative through their cultural diplomacy strategies.

Further exploring the tensions between the urban and the national, Nicholas Dines in the fifth paper, 'Moroccan city festival: cultural diplomacy and urban political agency', addresses the role of cultural festivals. He notes that during the last two decades, cultural festivals have been established and consolidated in cities across Morocco. Their proliferation has coincided with the reign of King Mohammed VI, well known as an enthusiastic and extremely wealthy patron of the arts, and the concomitant state-controlled democratization of Moroccan politics and society. They have also greatly benefitted from the Moroccan state's investment in urban and tourism infrastructures and the liberalization of the airline market with the European Union. The author reflects on how these urban festivals encourage a reframing of the relationship between city and nation state vis-à-vis the expected goals and unintended consequences of cultural diplomacy. In contrast to Morocco's national jamborees of the postindependence era, which celebrated arts and crafts and were geared to strengthening the bond between the population and the monarchy, the mission of today's urban festivals is less immediately tied to the content or experience of the event itself than to the city's capacity to highlight its organizational prowess and tourist appeal and to project a secular and tolerant approach to cultural and religious diversity to the outside world. Furthermore, these festivals do not target national and western audiences alone but are also increasingly aimed at Africa at large, reflecting Morocco's resurgent interest in playing an active role in the continent's economic, religious and cultural affairs. The author argues that the tensions that are often revealed-between the secular and the religious and between cultural elites and the urban poor-are precisely what makes these events particularly interesting for assessing the role of cities as cultural diplomacy actors in a non-western context.

The final sixth paper by Jasper Chalcraft, 'Into the Contact Zones of Heritage Diplomacy: local realities, transnational themes and internationalist expectations', explores the tensions between the local and the transnational by exploring the realm of 'heritage diplomacy' that he sees less as cultural relations, and more as a 'contact zone', a space where divergent viewpoints are brought together. The idea of heritage diplomacy as a 'contact zone' (Clifford 1997) highlights that heritage-making in (post-)conflict cultural relations is an ontological encounter between international agents and the traumatized communities for whom the stakes are, inevitably, higher. Mediated through the practice of heritage professionals, and through the visible pragmatism of civil society heritage activists, the impacts of heritage-making nevertheless remain complicated and entangled. Chalcraft develops a basic typology by contrasting the tension between the uses of 'charismatic heritage diplomacy' and more 'careful heritage diplomacy'. He then examines differences between local realities and international expectations by bringing together two case-studies: one from a Creative Europe-funded project where civil society actors develop strategies for working with the difficult heritage that lies behind nationalist myths, and the other from a British Council-funded programme dealing with endangered heritage in the MENA region. Critical studies of heritage-making often pitch the local against the international, with grassroots activities contrasted with international rhetoric surrounding heritage places, objects and practices. However, this dichotomy can mask other actors and social dynamics, not least the subtleties of how the collective traumas of conflict play out in the cultural field. 


\section{References}

Ang, I., Isar, Y. R., \& Mar, P. (2015). Cultural diplomacy: Beyond the national interest? International Journal of Cultural Policy, 21(5), 365-338.

Bourdieu, P. (1992). Language and symbolic power. Cambridge: Polity Press.

Bourdieu, P., \& Wacquant, L. J. D. (1992). An invitation to reflexive sociology. University of Chicago Press.

Caglar, A. \& Glick Schiller, N. (2015). A multiscalar perspective on cities and migration. Sociologica, 2/2015 (no page numbers).

English, J. F. (2005). The economy of prestige. Prizes, Awards and the Circulation of Cultural Value. Harvard University Press.

EUROCITIES. (2017) Cities' external cultural relations: Trends and actions. http://nws.eurocities. eu/MediaShell/media/EUROCITIES_study_on_culture_in_cities_external_relations_2017.pdf

Gaupp, L. (2020). The "west" versus "the rest"? Festival curators as gatekeepers for socio-cultural diversity. in V. Durrer and R Henze (eds) Managing culture: Reflecting on exchange in global times. Routledge.

Gibson, M., \& Moore, T. (2018). Cultural innovations on the fringe - The fields of 'limited' and 'extensive production. In J. Albright, D. Hartmann, \& J. Widin (Eds.), Bourdieu's field theory and the social sciences. Singapore: Palgrave Macmillan.

Isar, Y. R. (2010). Cultural diplomacy: An overplayed hand? Public Diplomacy Magazine, Winter 2010, $29-44$.

Isar, Y. R. (forthcoming) Civil society actors in international cultural diplomacy. In M. Hoelscher, et al. (eds.) Charting Global Challenges: Civil Society, the Nonprofit Sector and Culture (essays in honour of Helmut K. Anheier). Springer Verlag.

Kloot, B. (2009). Exploring the value of Bourdieu's framework in the context of institutional change. Studies in Higher Education, 34(4), 469-481.

Van Graan, M. (2018). Beyond curiosity and desire. Towards fairer international collaborations in the arts. IETM: Brussels.

Publisher's Note Springer Nature remains neutral with regard to jurisdictional claims in published maps and institutional affiliations. 